\title{
PROMENE FIZIČKOG FITNESA MUŠKARACA STARIJIH OD 60 GODINA - PILOT STUDIJA
}

\author{
Zoran Milanović ${ }^{1}$, Saša Pantelić ${ }^{1}$ i Bojan Jorgić ${ }^{1}$
}

${ }^{1}$ Fakultet sporta i fizičkog vaspitanja, Univerzitet u Nišu, Srbija

\section{SAŽETAK}

Cilj ovog istraživanja bio je da utvrdi razlike na polju funkcionalnog fitnesa kod muškaraca starijih od 60 godina. U istraživanje je bilo uključeno 272 ispitanika. Sve ispitanike smo podijelili u pet starosnih kategorija, i to: 60-64 godine bilo je 90 ispitanika (33\%), 65-69 godina, 70 ispitanika (26\%), 70-74 godine, 50 ispitanika (18\%), 75-79 godina, 41 ispitanik (15\%) i preko 80 godina starosti bio je 21 ispitanik $(8 \%)$. Svi ispitanici su proveli bateriju testova pod nazivom senior fitnes test. Test se sastoji od šest mjera fizičkog fitnesa: 1) pokretljivost ramena, 2) pretklon na stolici, 3) osam stopa, 4) ustajanje sa stolice za 30 sekundi, 4) fleksija u zglobu lakta, 5) dvominutni step test. Body mass index pokazuje da su svi ispitanici prekomjerne tjelesne težine bez obzira kojoj starosnoj kategoriji pripadaju. Kod fleksibilnosti ne postoji statistički značajna razlika $(\phi>0,05)$ između ispitanika različite starosne dobi nakon 60. godine starosti. Ispitanici se najviše razlikuju po pitanju snage kako donjih, tako i gornjih ekstremiteta. Primijećeno je opadanje snage sa procesom starenja tako da se ispitanici starosne dobi 60-64 godina statistički značajno razlikuju u snazi donjih ekstremiteta $(\phi<0,05)$ od ispitanika starih 70-74 i 75-79 godina. Najveća heterogenost zabilježena je u parametrima aerobne izdržljivosti, gdje rezultati progresivno opadaju od 60 godine, gdje su zabilježene najveće vrijednosti $(78,60 \pm 42,00)$ do 80 . godine starosti $(73,68 \pm 35,62)$. U ovoj studiji smo utvrdili da je došlo do povećanja količine masnog tkiva, smanjenja nivoa mišićne aktivnosti, kao i smanjenja mišićne snage i izdržljivosti procesom starenja.

Ključne riječi: fitness, senior fitnes test, stare osobe.

\section{UVOD}

Antropometrijske, funkcionalne i fitness karakteristike su usko povezane sa stilom života, zdravstvenim i funkcionalnim statusom starih osoba (Perissinotto, Pisent, Sergi i Grigoletto, 2002). Zbog toga je veoma teško dati standardne interpretacije njihovih vrijednosti. Sam proces starenja sa sobom nosi veliki broj fizioloških i nutritivnih promjena, kao što su smanjenje tjelesne mase, ali i tjelesne visine (Milanović, Pantelić, Trajković i Sporišs, 2011). Dobro je poznato da su prekomjerna tjelesna masa i gojaznost usko povezane sa povećanjem rizika od nastanka kardiovaskularnih bolesti, zatim hroničnih oboljenja i smanjene funkcije pokretljivosti tijela (Musta i saradnici, 1999).

Longitudinalna studija (Visser i saradnici, 2003) pokazuje da tjelesna masa opada kod starih muškaraca i žena nakon 60 . godine života. Takođe, težina tijela se značajno razlikuje između muškaraca i žena $(70,3$ prema $62,7 \mathrm{~kg}$ ) kao i visina (163 prema $152 \mathrm{~cm}$ ) prema studiji Sánche García i saradnici (2007), što su potvrdile i druge studije (Reddy i Papa Rao, 2010; Setiati i saradnici, 2010). Smatra se da je 75 . godina života prekretnica po pitanju BMI i antropometrijskih mjera i kod muškaraca i kod žena.

Bez obzira na ove antropometrijske promjene, nivo funkcionalnog fitnesa se često koristi kao parametar praćenja i procjene zdravlja stanovništva i gotovo uvijek se povezuje sa zdravstvenim statusom. Njega možemo definisati kao fizički kapacitet za obavljanje svakodnevnih aktivnosti, nezavisno i bez pojave zamora, koji uključuje komponente kao što su: mišićna snaga i fleksibilnost donjih i gornjih ekstremiteta, aerobna izdržljivost i motorna agilnost/ dinamički balans (Rikli i Jones, 2001). Ovo praćenje je posebno važno kod starijih osoba iznad 60 godina zbog 
sprečavanja nastanka mnogih oboljenja, pojave inaktiviteta, ali i smanjenje stope mortaliteta. Nesumnjivo je jasno da fizičke aktivnosti utiču na odlaganje nastanka oboljenja i inaktiviteta, dok u isto vrijeme podižu funkcionalne sposobnosti koje mogu da se održe i nakon prestanka vježbanja (Toraman, Ayceman i Yaman, 2005).

Međutim, postoje brojne prepreke kada je riječ o uključivanju starih osoba u proces fizičkog vježbanja bez obzira na karakter same vježbe. Pol je jedan od uticajnih faktora učešća starih osoba u sportsko rekreativnim aktivnostima (Trost, Owen, Bauman, Sallis i Brown, 2002), tako da je potrebno ispitati potencijalne determinante fizičke aktivnosti odvojeno za svaki pol. Utvrđeno je da žene imaju niži nivo učešća u sportsko- rekreativnim aktivnostima u odnosu na muškarce starosne dobi 60> (Leslie, Fotheringham, Owen i Bauman, 2001). Studija Moschny, Platen, Klaaben Mielke, Trampisch i Hinrichs (2011) koja je paralelno pratila sportske aktivnosti i kućne poslove, zaključila je da su muškarci angažovaniji u sportskim aktivnostima od žena (01:45 nasuprot 01:10 h), ali žene provode nedeljno više vremena u kućnim poslovima od muškaraca (04:00 nasuprot 03:00 h).

Odvojene analize različitih aktivnosti bi pomogle za razumijevanje učešća u različitim aktivnostima. Međutim, prema saznanju autora, postojeće studije su fokusirane na ispitivanje potencijalnih oblika fizičke aktivnosti kod starijih osoba koje su isključivo fokusirane na jednu vrstu aktivnosti, ocjenjujući samo muškarce, ili samo žene, ili pokazujući rezultate ukupnih aktivnosti (Ashe, Miller, Eng i Noreau, 2008; Chad i saradnici, 2005; Haley i Andel, 2010; Kaplan, Newsom, McFarland i Lu, 2001; Lawlor, Taylor, Bedford i Ebrahim, 2002; Ruchlin i Lachs, 1999; Walsh, Pressman, Cauley i Browner, 2001).

Pretpostavili smo da proces starenja sa sobom nosi i određene promjene kod antropometrijskih i fitnes parametara muškaraca starijih od 60 godina. Stoga je primarni cilj ovog istraživanja bio da utvrdi razlike na polju funkcionalnog fitnesa kod muškaraca starijih od 60 godina, podijeljenih u pet starosne kategorije. Sekundarni cilj bio je da utvrdimo koja od pet starosnih kategorija (60-64, 65-69, 70-74, 75-79 i preko 80 godina) sa sobom nosi najveće promjene.

\section{TABELA 1}

Generalni deskriptioni parametri $(M \pm S D)$.

\begin{tabular}{ccccc}
\hline $\begin{array}{c}\text { Uzrasna } \\
\text { ketagorija }\end{array}$ & $n(\%)$ & $\begin{array}{c}\text { Tjelesna visina } \\
(\mathrm{cm})\end{array}$ & $\begin{array}{c}\text { Tjelesna težina } \\
(\mathrm{kg})\end{array}$ & $\begin{array}{c}\text { BMI } \\
\left(\mathrm{kg} / \mathrm{m}^{2}\right)\end{array}$ \\
\hline $60-64$ & $90(33 \%)$ & $178,19 \pm 6,65$ & $80,88 \pm 9,59$ & $25,50 \pm 3,02$ \\
\hline $65-69$ & $70(26 \%)$ & $177,00 \pm 9,35$ & $84,54 \pm 13,81$ & $27,03 \pm 4,15$ \\
\hline $70-74$ & $50(18 \%)$ & $174,50 \pm 7,71$ & $79,78 \pm 11,69$ & $26,27 \pm 4,00$ \\
\hline $75-79$ & $41(15 \%)$ & $175,34 \pm 7,79$ & $78,27 \pm 13,13$ & $25,39 \pm 3,67$ \\
\hline $80>$ & $21(8 \%)$ & $176,43 \pm 8,95$ & $78,48 \pm 10,44$ & $25,25 \pm 3,20$ \\
\hline Total & 272 & $176,64 \pm 8,02$ & $81,04 \pm 11,93$ & $26,00 \pm 3,68$ \\
\hline
\end{tabular}

Legenda: $\boldsymbol{n}$ - Broj ispitanika; $B M I$ - Indeks tjelesne mase; $\boldsymbol{M}$ - Aritmetička sredina;

$S D$ - Standardna devijacija.

\section{METODE}

\section{Ispitanici}

Dvije stotine sedamdeset i dva nasumično odabrana ispitanika bilo je uključeno u ovo istraživanje. Sve ispitanike podijelili smo u pet starosnih kategorija $i$ to: 60-64 godine gdje je bilo 90 ispitanika (33\%), 65-69 godina, 70 ispitanika (26\%), 70-74 godine, 50 ispitanika (18\%), od 75-79 godina, 41 ispitanik (15\%) i preko 80 godina starosti bio je 21 ispitanik (8\%). Generalni deskriptivni parametri ispitanika prikazani su u Tabeli 1. Starosna dob ispitanika kretala se u rasponu 60-91 godine. Učešće u studiji bilo je dobrovoljno i svako od ispitanika je mogao da se povuče u bilo kom trenutku testiranja. Istraživanje je odobreno od strane Etičke komisije Fakulteta sporta i fizičkog vaspitanja Univerziteta u Nišu, u skladu sa Helsinškom deklaracijom. Svi ispitanici su najprije informisani o eventualnim posljedicama testiranja, kao i o prednostima koje ovo istraživanje donosi njihovoj dobnoj populaciji. Testiranje svih ispitanika bilo je u periodu od oktobra do decembra mjeseca 2011. godine. Svi ispitanici bili su mentalno i fizički sposobni da učestvuju u studiji. Kriterijumi za izbor učesnika u ovoj studiji bili su: starost između 60 i 80 godina, fizički nezavisne osobe - u stanju da hodaju 
20 metara bez pomoći ili pauze, bez kognitivnog oštećenja i demencije, tako da njihov zbir u mini mental skali iznosi 24 poena za obrazovanim i 18 poena za neobrazovane (McDowell i Newell, 1996). Ispitanici koji su bili u fazi oporavka od neke akutne bolesti, zatim gluvi i slijepi, bili su isključeni. Takođe, istraživanjem nisu obuhvaćene osobe sa poremećajem kardiovaskularnog sistema zbog potencijalnih rizika tokom testiranja fizičkog fitnesa.

Obučene osobe za potrebe ovog istraživanja su najprije obavile standardni intervju sa potencijalnim ispitanicima individualno ili u malim grupama, kod njihovih kuća ili u aktivnim centrima za stare osobe. Svaki od ispitanika je najprije dao svoje demografske karakteristike, a zatim se pristupilo mjerenju antropometrijskih mjera i senior fitnes testa (SFT). Antropometrijske mjere

Antropometrijske mjere, mjerene su u skladu sa preporukama Internacionalnog biološkog programa - IBP (Weiner i Lourie, 1969). Visina tijela mjerena je mjernom trakom, sa tačnošću $0,1 \mathrm{~cm}$. Težina tijela procijenjena je pomoću decimalne vage, sa tačnošću $0,1 \mathrm{~kg}$. Body mass index (BMI) izračunat je indirektno na osnovu zabilježenih vrijednosti mase i visine tijela, pomoću formule $\mathrm{BMI}=$ masa tijela $(\mathrm{kg}) /$ visina tijela $\left(\mathrm{m}^{2}\right)$.

\section{Senior fintes test}

Senior fintes test je baterija testova za procjenu funkcionalnog fitnesa starijih osoba. Ovaj test procjenjuje fiziološki kapacitet za izvođenje normalnih svakodnevnih aktivnosti, nezavisno i bezbjedno, bez pojave zamora. Prije izvođenje testa, ispitanici najprije odrade desetominutno zagrijevanje, vođeno od strane obučenih osoba, a zatim izvode kompletan SFT po redoslijedu zadataka koji se navode u ovom testu (Rikli i Jones, 2001). Ovaj test je potvrđen od strane Rikli i Jones (1999). Test se sastoji od šest mjera fizičkog fitnesa: 1) pokretljivost ramena, 2) pretklon na stolici, 3) osam stopa, 4) ustajanje sa stolice za 30 sekundi, 4) fleksija u zglobu lakta, 5) dvominutni step test. Pokretljivost ramena procjenjuje fleksibilnost gornjih ekstremiteta. Svaki ispitanik izvodi po dva probna pokušaja i dva pokušaja koja se mjere i ulaze u dalju analizu. Rezultat predstavlja najkraća udaljenost između opruženog srednjeg prsta obje ruke. Pretklon na stolici je test koji je procjenjuje fleksibilnost donjih ekstremiteta. Kao i kod prethodnog testa, svaki ispitanik izvodi po dva probna pokušaja i dva pokušaja koja se mjere i ulaze u dalju analizu. Rezultat predstavlja najveća distanca između opruženih prstiju ruke i vrhova nožnih prstiju. Test 8 stopa procjenjuje agilnost i dinamički balans. Svaki od ispitanika izvodi jedan probni pokušaj i dva koja se mjere i kasnije analiziraju. Rezultat je najkraće vrijeme postignuto od trenutka ustajanja sa stolice, pređenih osam stopa, okreta i povratka u sjedeću poziciju. Ustajanje sa stolice je test kojim se procjenjuje snaga donjih ekstremiteta. Svaki ispitanik ima dva probna pokušaja, a zatim se pristupa protokolu mjerenja koji podrazumijeva maksimalni broj ustajanja koje može da izvede ispitanik za 30 sekundi. Test fleksija u zglobu lakta procjenjuje snagu gornjih ekstremiteta. Svaki od ispitanika najprije uradi dva probna pokušaja, a zatim kompletira test $u$ trajanju od 30 sekundi. Kao rezultat računa se ukupan broj ponavljanja, sa rasponom pokreta izvedenih u 30 sekundi. Dvominutni step test je test kojim se procjenjuje mišićna izdržljivost. Ispitanik okrenut licem prema zidu, treba da izvede maksimalni broj koraka do zadate visine u dva minuta. Test se izvodi samo jednom, a ispitanik za vrijeme ovog testa ne trči, već hoda što je brže moguće.

\section{Statistička analiza}

Prikupljeni podaci obrađeni su pomoću statističkog programa SPSS 17.0 (SPSS Inc., Chicago, IL). Deskriptivni statistički parametri izračunati su za svaku varijablu. Za utvrđivanje razlike između starosne kategorije kojoj ispitanici pripadaju korišćena je univarijantna analiza varijanse (ANOVA). Za utvrđivanje statistički značajnih razlika između grupa starosne dobi primijenjena je Bonferonijeva korekcija. Statistička značajnost bila je $p<0,05$.

\section{REZULTATI}

Najveći broj ispitanika bio je u starosnoj kategoriji 60-64 godine (33\%), dok je sa porastom broja godina broja ispitanika opadao, tako da je u kategoriji preko 80 godina starosti bilo svega $8 \%$ ispitanika. Tjelesna visina bila je dosta ujednačena između grupa i kretala se u rasponu od 178,19 \pm 6,65 cm kod osoba 60-64 godine starosti, do $174,50 \pm 7,71 \mathrm{~cm}$ kod osoba 10 godina starijih (70-74 godine starosti). Takođe statistički značajna razlika nije pronađena ni kada je tjelesna masa u pitanju $(\phi>0,05)$. Posmatrani kroz sferu body mass index-a, svi ispitanici su prekomerne tjelesne težine bez obzira kojoj starosnoj kategoriji pripadaju (Tabela 1). Najveće vrijednosti BMI zabilježene su kod muškaraca starosti 65-69 godina (BMI $=27,03$ $\left.\pm 4,15 \mathrm{~kg} / \mathrm{m}^{2}\right)$, dok je najniža kod najstarijih ispitanika, preko 80 godina starosti, i iznosi 25,25 $\pm 3,20 \mathrm{~kg} /$ $\mathrm{m}^{2}$.

Iz Tabele 2 vidimo da kada je riječ o fleksibilnosti, ne postoji statistički značajna razlika između ispitanika različite starosne dobi nakon 60 godina starosti. Takođe, 
u parametrima za procjenu agilnosti i dinamičkog balansa (osam stopa test), nije utvrđena statistički značajna razlika između grupa. Ispitanici se najviše razlikuju po pitanju snage kako donjih, tako i gornjih ekstremiteta. Primijećeno je opadanje snage sa procesom starenja tako da se ispitanici starosne dobio 60-64 godine statistički značajno razlikuju u snazi donjih ekstremiteta $(p<0,05)$ od ispitanika starih 70-74 i
75-79 godina starosti. Kada je riječ o gornjim ekstremitetima, razlikuju se grupe ljudi od 60-64 i 70-74 (18,16 \pm 4,87 nasuprot 16,37 $\pm 5,90$ ponavljanja) godine starosti. Najveća heterogenost zabeležena je u parametrima aerobne izdržljivosti gdje rezultati progresivno opadaju od 60 godine, i tu su zabilježene najveće vrijednosti $(78,60 \pm 42)$ do 80 godine starosti

TABELA 2

Parametri senior fitness testa po starosnim kategorijama ( $M \pm S D)$.

\begin{tabular}{lccccc}
\hline & \multicolumn{5}{c}{ Muškarci } \\
\cline { 2 - 5 } & $60-64$ & $65-69$ & $70-74$ & $75-79$ & $80>$ \\
\hline Pokretljivost ramena (cm) & $-6,45 \pm 8,90$ & $-9,03 \pm 9,23$ & $-9,85 \pm 12,78$ & $-7,98 \pm 11,61$ & $-10,74 \pm 11,50$ \\
\hline Pretklon na stolici (cm) & $0,11 \pm 6,87$ & $-0,60 \pm 10,53$ & $4,05 \pm 9,43$ & $1,38 \pm 8,24$ & $0,73 \pm 9,00$ \\
\hline Osam stopa (sec) & $7,52 \pm 6,54$ & $8,10 \pm 2,91$ & $9,84 \pm 8,88$ & $7,84 \pm 3,34$ & $7,97 \pm 3,34$ \\
\hline Ustajanje sa stolice za 30 & $15,34 \pm 4,32^{\Omega \#}$ & $13,90 \pm 5,87$ & $14,45 \pm 5,05^{\Omega}$ & $12,43 \pm 5,24^{\#}$ & $12,74 \pm 5,10$ \\
sekundi (rep) & $18,16 \pm 4,87^{\Omega}$ & $16,54 \pm 6,19$ & $16,37 \pm 5,90^{\Omega}$ & $16,76 \pm 7,08$ & $16,79 \pm 5,11$ \\
\hline Fleksija u zglobu lakta (rep) & $78,60 \pm 42,90^{\Omega \#}$ & $75,64 \pm 57,80^{\ddagger}$ & $67,44 \pm 33,92^{\Omega}$ & $55,46 \pm 40,97^{\# \ddagger}$ & $73,68 \pm 35,62$ \\
\hline Dvominutni step test (rep) & 78,450
\end{tabular}

Legenda: * - Statistički značajna razlika između starosne dobi 65-69 i 70-74; ^ - Statistički značajna razlika između starosne dobi 65-69 i 80>; † - Statistički značajna razlika između starosne dobi 60-64 i 65-69; ¥ - Statistički značajna razlika između starosne dobi 65-69 i 75-79; ${ }^{\mathbf{\Omega}}$ - Statistički značajna razlika izmedju starosne dobi 60-64 i 70-74; \# - Statistički značajna razlika izmedju starosne dobi 60-64 i 75-79; rep - Ponavlanja.

\section{DISKUSIJA}

Promocija zdravog stila života starih osoba postaje značajnija zbog dramatičnog uvećanja broja ovih osoba tokom posljednje dvije decenije. Nivo fizičke aktivnosti se često koristi kao parametar praćenja i procjene javnog zdravlja stanovništva. Ovo praćenje je posebno važno kod starih osoba zbog prevencije mnogih oboljenja, nastanka inaktiviteta, ali i smanjenje stope mortaliteta (Milanović i saradnici, 2011).

Prosečna tjelesna visina i težina ispitanika bila je $176,64 \pm 8,02 \mathrm{~cm}, 81,04 \pm 11,93 \mathrm{~kg}$, što je daleko više od rezultata prikazanih u studiji Velazguez-Alva i saradnici (1996) (163,8 \pm 5,53 cm, 70,07 \pm 9,92 kg). Rezultati našeg istraživanja su slični sa rezultatima studije (Cicioglu, 2010; Sánchez García i saradnici, 2007; Setiati i saradnici, 2010). Rezultati slične studije (Guo, Zeller, Chumlea i Siervogel; 1990) koja pokazuju da se ukupna tjelesna masa povećava od 60 do 70 godina starosti. Međutim, u studiji Viser i saradnici (2003) tjelesna težina se povećava nakon 60 godine, što je suprotno našim rezultatima. Vrijednosti BMI pokazuju da su ispitanici u ovoj studiji prekomerne tjelesne težine $($ BMI > 25), koja može da dovede do pojave različitih hroničnih oboljenja i smanjenja sposobnosti (Pai, 2011; Perissinotto i saradnici, 2002). Gojaznost je jedan od najučestalijih javnozdravstvenih problema na koji se može efektivno preventivno djelovati (Milanović i saradnici, 2011). Perissinoto i saradnici (2002) su pronašli niže vrijednosti BMI između starosne dobi 65-75 nego u periodu između 75-80 godina života, što je suprotno našim rezultatima. Rezultati ove studije su samo potvrdili trend povećanje broja gojaznih starih osoba u posljednje dvije decenije, (Misra i Khurana, 2008). Starenje je povezano sa povećanjem udela masnog tkiva i preraspodele tjelesne masti. Preraspodela masti pretežno iz donjeg dela tijela u abdominalni i visceralni dio je najčešće zastupljena kod starih osoba. Smanjenje BMI nastaje zbog gubitka mišićne mase i povećanja masnog tkiva u predjelu struka i kukova.

S obzirom da smo u ovoj studiji analizirali samo parametar BMI, izostaje jasnija slika o preraspodjeli tjelesnih masti kod ispitanika, a koja je neophodna za buduća istraživanja. U našoj studiji primjetno je smanjenje mišićne snage kako donjih, tako i gornjih 
ekstremiteta progresivno sa povećanjem broja godina. Smanjenje mišićne snage tokom procesa starenja rezultat je značajnog gubitka mišićne mase, što može da prouzrokuje i smanjenje fizičke aktivnosti (Радовановић \& Игњатовић, 2009), ali i povećanje rizika od padova i nastanka povreda kod starijih osoba. Sedentarni način života ima značajan uticaj na mišićnu masu i povećanje potkožnog masnog tkiva. Rezultati ove studije očigledno pokazuju da su muškarci manje fizički aktivni sa procesom starenja, što se može odraziti na njihovu mišićnu snagu i izdržljivost. Naša studija pokazuje statistički značajno smanjenje aerobne izdržljivosti kod ispitanika 60-64 godine i onih starijih od 75 godina. Dakle, smanjenje funkcije mišića treba pripisati kombinaciji faktora kao što su starenje i smanjena fizička aktivnost (Shephard, 1997; Spirdusso, 1995). Potvrdu ovome daje studija Jozsi, Campbell, Joseph, Davey i Evans (1999) i Toraman i saradnici
(2005), koja je ustanovila da se adekvatnim treningom može održati mišićna snaga i izdržljivost. Drugi razlog smanjenja mišićne snage i izdržljivosti jeste smanjenje broja mišićnih vlakana tokom procesa starenja. Rezultati istraživanja pokazuju da se gubi približno $10 \%$ mišićnih vlakana u toku svake decenije nakon 50 . godine života (Lexell, Taylor i Sjöström, 1988). Sa druge strane, proces starenja dovodi do redukcije u aktivaciji motornih jedinica (Радовановић \& Игњатовић, 2009).

Možemo zaključiti da je došlo do povećanja količine masnog tkiva, uz redukciju nivoa mišićne aktivnosti. Pored toga, može se konstatovati da se procesom starenja smanjuje mišićna snaga i izdržljivost starih osoba. Ovi parametri mogu dovesti do povećanja rizika nastanka kardiovaskularnih i respiratornih bolesti. Prema tome njihove radne sposobnosti i fizički fitnes su mnogostruko smanjeni. Negativne faktore bi trebalo ukloniti u cilju prevencije gojaznosti i gore navedenih

\section{SLIKA 1}

Trend promena fizičkog fitnesa u odnosu na godine starosti.
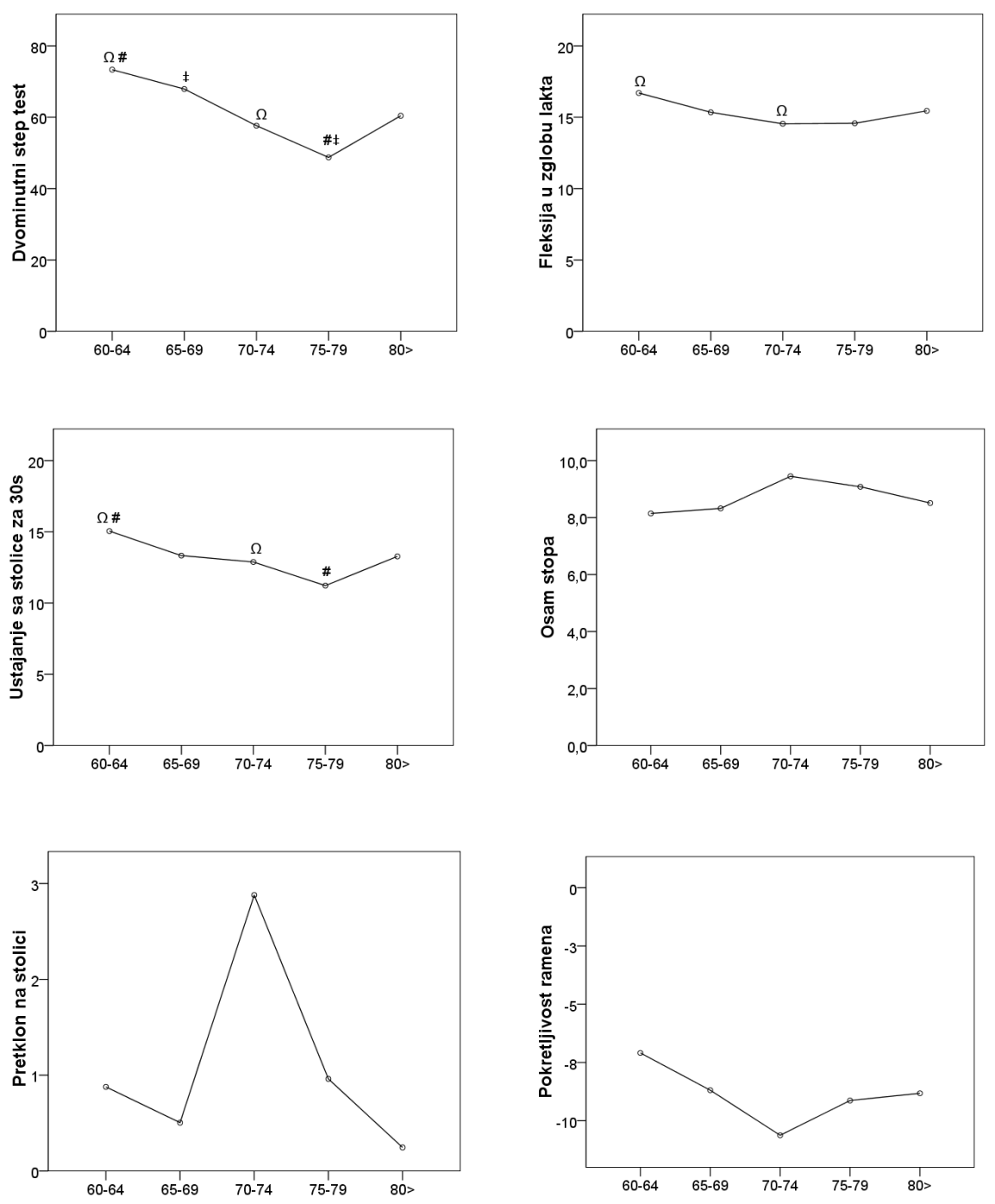
bolesti. Smanjenje tjelesnih masti može da dovede do boljeg nivoa fizičkog fitnesa i radnog kapaciteta. Regularna fizička aktivnost i funkcionalni fitnes mogu da uspore proces starenja.

\section{ZAHVALNOST}

Ovo istraživanje je sprovedeno u okviru projekta "Fizička aktivnost i fitnes komponente starih" koji je odobren 2010, a finansirano od strane Ministarstva prosvete i nauke Republike Srbije (broj 179056). Ovaj projekat sprovodi Fakultet sporta i fizičkog vaspitanja Univerziteta u Nišu.

\section{LITERATURA}

Ashe, M. C., Miller, W. C., Eng, J. J., \& Noreau, L. (2008). Older Adults, Chronic Disease and Leisure-Time Physical Activity. Gerontology, 55, 64-72. doi: 10.1159/000141518; PMid: 18566534; PMCid: 3167824

Chad, K. E., Reeder, B. A., Harrison, E. L., Ashworth, N. L., Sheppard, S. M., Schultz, S. L. ... Lawson, J. A. (2005). Profile of physical activity levels in community-dwelling older adults. Medicine and Science in Sport and Exercises, 37, 1774-1784. doi: 10.1249/01. mss.0000181303.51937.9c

Cicioglu, I. (2010). Assessment of Physical Fitness Levels of Elderly Turkish Males over 60 Years. Collegium Antropologicum, 34(4), 1323-1327. PMid: 21874716

Garcia, S. S., Perla, G. C., Lopez, D. M., Cedillo, H. T., Nunez, C. A. R., \& Beamen, R. S. (2007). Anthropometric measures and nutritional status in helathy elderly population. BMC Public Helath, 7, 2-15. doi: 10.1186/1471-2458-7-2; PMid: 17201919; PMCid: 1769489.

Guo, S. S., Zeller, C., Chumlea, W. C., \& Siervogel, R. M. (1999). Aging, body composition, and lifestyle, the Fels Longitudinal Study. American Journal of Clinical Nutrition, 70(3), 405-411. PMid: 10479203

Haley, C., \& Andel, R. (2010). Correlates of Physical Activity Participation in CommunityDwelling Older Adults. Journal of Aging and Physical Activity, 18, 375-389. PMid: 20956840

Jozsi, A. C., Campbell, W. W., Joseph, L., Davey, S. L., \& Evans, W. J. (1999). Changes in power with resistance training in older and younger men and women. The journals of gerontology Series A Biological sciences and medical sciences, 54(11), M591-M596. doi: 10.1093/gerona/54.11.M591 Kaplan, M. S., Newsom, J. T., McFarland, B. H., \& Lu, L. N. (2001). Demographic and psychosocial correlates of physical activity in late life. American Journal of Preventive Medicine, 21, 306-312. doi: 10.1016/S0749-3797(01)00364-6

Lawlor, D. A., Taylor, M., Bedford, C., \& Ebrahim, S. (2002). Is housework good for health? Levels of physical activity and factors associated with activity in elderly women. Results from the British Women's Heart and Health Study. Journal of Epidemiology \& Community Health, 56, 473-478. doi: 10.1136/jech.56.6.473

Leslie, E., Fotheringham, M. J., Owen, N., \& Bauman, A. (2001). Age-related differences in physical activity levels of young adults. Medicine \& Science in Sports \& Exercise, 33, 255-258. doi: 10.1097/00005768-200102000-00014; PMid:11224815

Lexell, J., Taylor, C. C., \& Sjöström, M. (1988). What is the cause of the ageing atrophy? Total number, size and proportion of different fiber types studied in whole vastus lateralis muscle from 15- to 83-year-old men. Journal of the Neurological Sciences, 84(2-3), 275-294. doi: 10.1016/0022-510X(88)90132-3

McDowell, I., \& Newell, C. (1996). Mental status testing Measuring health: a guide to rating scales and questionnaire. New York: Oxford University Press.

Milanović, Z., Pantelić, S., Trajković, N., \& Sporiš, G. (2011). Basic anthropometric and body composition characteristics in elderly population: A Systematic Review. Facta Universitatis: Series Physical Education and Sport, 9(2), 173-182.

Misra, A., \& Khurana, L. (2008). Obesity and the metabolic syndrome in developing countries. The Journal of Clinical Endocrinology \& Metabolism, 93, S9-S30. doi: 10.1210/jc.2008-1595

Moschny, A., Platen, P., Klaaben-Mielke, R., Trampisch, U., \& Hinrichs, T. (2011). Physical activity patterns in older men and women in Germany: a cross-sectional study. BMC Public Health, 11(1), 559-572. doi: 10.1186/14712458-11-559; PMid: 21752288; PMCid: 3154867

Musta, A., Spadano, J., Coakley, E. H., Field, A. E., Colditz, G., \& Dietz, W. H. (1999). The disease burden with overweight and obesity. Journal of American Medical Association, 282(16), 1523-1532. doi: $10.1001 /$ jama.282.16.1523

Pai, M. K. (2011). Comparative study of nutritional status of elderly population living in the home for aged vs those living in the community. Biomedical Research, 22(1), 120-126.

Perissinotto, E., Pisent, C., Sergi, G., \& Grigoletto, F. (2002). Anthropometric measurements in the 
elderly, age and gender differences. British Journal of Nutrition, 87(2), 177-86. doi: 10.1079/ BJN2001487

Радовановић, А., \& Игњатовић, А. (2009). Физиолошке основе тренинга силе и снаге [Physiological basis of force and strength practice]. Niš, SRB: Faculty of sport and physical education.

Reddy, K. K., \& Papa Rao A. (2010). Nutritional Status and Impaired Functional Ability Among the Elderly. The Open Anthropology Journal, 3, 192-199. doi: 10.2174/1874912701003030192

Rikli, R. E., \& Jones, C. J. (1999). Development and validation of a functional fitness test for community-residing older adults. Journal of Aging and Physical Activity, 17, 127-159.

Rikli, R. E., \& Jones, C. J. (2001). Senior Fitness Test Manual. Champaign, IL: Human Kinetics.

Ruchlin, H. S., \& Lachs, M. S. (1999). Prevalence and correlates of exercise among older adults. Journal of Applied Gerontology, 18, 341-357. doi: 10.1177/073346489901800305

Sánchez García, S., García Peña, C., Duque López, M. X., Juárez-Cedillo, T., Cortés-Núñez, A. R., \& Reyes-Beaman, S. (2007). Anthropometric measures and nutritional status in a healthy elderly population. BMC Public Health, 7, 2. doi: 10.1186/1471-2458-7-2; PMid: 17201919; PMCid: 1769489

Setiati, S., Istanti, R., Andayani, R., Kuswardhani, R.A., Aryana, I.G., Putu, I.D., ... S. Mustika. (2010). Cut-off of anthropometry measurement and nutritional status among elderly outpatient in Indonesia, multi-centre study. Acta Medica Indonesiana, 42(4), 224-254. PMid: 21063044
Shephard, J. (1997). Aging, physical activity and health. Champaign, IL: Human Kinetics.

Spirdusso, W. W. (1995). Physical dimension of aging. Champaign, IL: Human Kinetics.

Toraman, N., Ayceman, N., \& Yaman, H. (2005). Effects of six weeks of detraining on retention of functional fitness of old people after nine weeks of multicomponent training. British Journal of Sports Medicine, 39(8), 565-568. doi: 10.1136/bjsm.2004.015586; PMid: 16046345; PMCid: 1725289

Trost, S. G., Owen, N., Bauman, A. E., Sallis, J. F., \& Brown, W. (2002). Correlates of adults 'participation in physical activity: review and update. Medicine \& Science in Sports \& Exercise, 34, 1996-2001. doi: 10.1097/00005768200212000-00020

Visser, M., Pahor, M., Tylavsky, F., Kritchevsky, S. B., Cauley, J. A., Newman, A., \& T. B. Harris. (2003). One- and two-year change in body composition as measured by DXA in a population-based cohort of older men and women. Journal of Applied Physiology, 94(6), 2368-2374. PMid: 12598481

Walsh, J. M. E., Pressman, A. R., Cauley, J. A., \& Browner, W. S. (2001). Predictors of physical activity in community-dwelling elderly white women. The Journal of General Internal Medicine, 16, 721-727. doi: 10.1111/j.1525-1497. 2001.00506.x; PMid: 11722684; PMCid:1495288

Weiner J., \& Lourie E. (1969). Human Biology: A Guide to Field Metods, International Biological programme. Oxford - Edinburgh, Great Britain: Blackwell Scientific Publications.

Primljeno: 2. februara 2012. godine Izmjene primljene: 4. aprila 2012. godine Odobreno: 1. maja, 2012. godine

Korespodencija: Dr Saša Pantelić

Fakultet sporta i fizičkog vaspitanja Čarnojevićeva 10a $18000 \mathrm{Nišs}$ Srbija

E-mail: spantelic2002@yahoo.com Telefon: 00381641365229 